\title{
The theoretical comparison between two model NO carriers, MeSNO and MeSeNO
}

\author{
Chin-Hung Lai $\cdot$ Pi-Tai Chou
}

Received: 22 May 2007 / Accepted: 12 September 2007 / Published online: 17 October 2007

(C) Springer-Verlag 2007

\begin{abstract}
In this study, we apply a hybrid DFT functional, MPW1LYP, to make a comparison between MeSNO and MeSeNO. Due to the mesomeric effect and negative hyperconjugation, Se-nitrososelenols seem to be more unstable than S-nitrosothiols regarding unimolecular decomposition. Interestingly, however, the barrier of the transnitrosation reaction of MeSeNO is larger than that of MeSNO, disregarding nucleophiles in the gas phase. Using the polarizable continuum model to consider the water solvent effect, the transnitrosation reactions of MeXNO and $\mathrm{YMe}^{-}(\mathrm{X}=\mathrm{S}, \mathrm{Se} ; \mathrm{Y}=\mathrm{S}, \mathrm{Se})$ are found to undergo concerted reactions, in sharp contrast to the two-step reaction pathways concluded in the gas phase. Moreover, the barriers of the transnitrosation reactions of MeSNO for nucleophiles $\mathrm{SMe}^{-}$and $\mathrm{SeMe}^{-}$from the gas phase to the aqueous solution are found to be decreased, while the transnitrosation reactions of $\mathrm{MeSeNO}$ are essentially barrierless in aqueous solution.
\end{abstract}

Keywords DFT. MPW1LYP. S-Nitrosothiol .

Se-Nitrososelenol · Transnitrosation reaction .

Polarizable continuum model

\section{Introduction}

Nitric oxide, which acts as an important biological messenger in the cardiovascular system, has been known for more than a decade. It has been suggested that NO is stored by a carrier

C.-H. Lai $(\bowtie) \cdot$ P.-T. Chou

Department of Chemistry, National Taiwan University,

106 Taipei, Taiwan, Republic of China

e-mail: chinhunglai@ntu.edu.tw molecule that preserves its biological activity [1-3]. Low molecular weight thiols, such as cysteine and glutathione (GSH), are prime candidates for such carrier molecules because they can form S-nitrosothiols (RSNOs) with NO. Also, RSNOs have been found to exhibit a variety of biological properties similar to those of NO, including vasodilation of arteries, inhibition of platelet aggregation, smooth muscular cell proliferation, etc. [4-9]. Previous studies on the physiological chemistry of RSNOs indicate that they can undergo transnitrosation reactions (see Scheme 1) [10-15]. The transfer of NO between different thiols via transnitrosation is largely responsible for the activity of RSNO in vivo, and has been suggested to be a signaling mechanism for the control of cellular processes by NO [16, 17]. Additionally, S-nitrosation of cysteine has been proposed as a key factor in the regulation of protein function [18]. It is well established that the transnitrosation reaction is a reversible second-order reaction, namely first order for S-nitrosothiol and first order for thiol [19]. According to previous studies, the rate of transnitrosation is diminished by steric hindrance at the thiol group and is increased by an increase in thiol acidity, elevated $\mathrm{pH}$, and enhanced electrophilicity of the nitrosothiol. These observations are in accordance with an $\mathrm{S}_{\mathrm{N}} 2$ reaction, in which an electrophilic RSNO is attacked by a nucleophilic thiolate anion, as shown in Scheme 1. Electrospray ionization mass spectrometry, NMR and theoretical calculations have further proved the existence of an anionic intermediate, i.e. nitroxyl disulfide, during this reaction [20-23]. For example, following infusion of S-Nitroso-N-acetyl-penicillamine (SNAP, $10 \mathrm{mM}$ ) in acetonitrile through an electrospray nebulizer into an Agilent 1100LC/MSD ion trap, ions were detected in a negative ion mode. The total ion spectrum showed a strong peak, characterized as the SNAP carboxylate anion (m/e 219) [20]. 


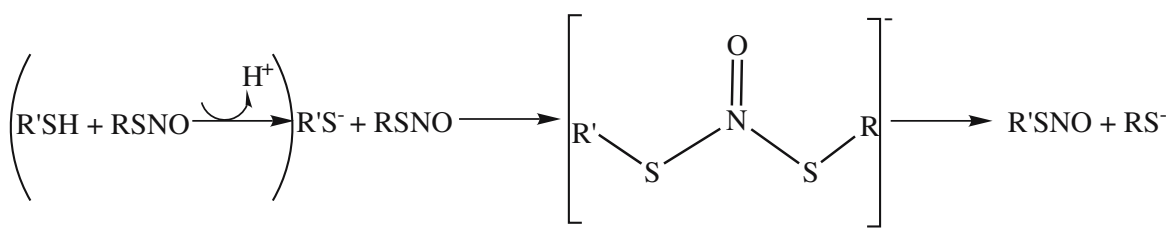

(is stepwise in the gas phase but concered in the aqueous solution at $310 \mathrm{~K}$ )

Scheme 1 The proposed mechanism of transnitrosation

Recently, there have been several reports suggesting that the interactions of NO (or NO-derived species) with the $\mathrm{SeH}$ groups of selenoproteins are also involved in NOmediated cellular functions [24-30]. For example, an essential selenium-containing antioxidant enzyme called glutathione peroxidase (GPx) can be inactivated by treating it with RSNO or endogenous NO [20-25], presumably through the Se-nitrosation of selenocysteine [25, 27]. In contrast to the extensive studies undertaken on S-nitrosothiols, however, chemical information about their selenium analogues is lacking to date despite their potential physiological importance [31]. To elucidate the mechanism of NOmediated modification of selenoproteins, reference data on Se-nitrosated species are thus indispensable. In this area, Nagase and coworkers synthesized a Se-nitroselenol and calculated its spectral properties [32], and Becker and coworkers discussed the homolysis of Se-nitrososelenol [31]. Owing to the weak $4 p-2 p$ orbital overlap, the selenium-nitrogen bond of the SeNO group is expected to be weaker than the sulfur-nitrogen bond of the SNO group, such that Se-nitrososelenols are likely to be more labile than S-nitrosothiols. Accordingly, Se-nitrososelenols are kinetically stabilized by bulky ligands to prevent them from reacting with neighboring molecules. For example, Goto and coworkers synthesized a stable Senitrososelenol [33] by taking advantage of bowl-type steric protection groups like Bpq [34], and investigated the related thermolysis and photolysis [35]. Unfortunately, despite such elegant studies, there is still insufficient information about the relevant reactions of these molecules, especially in the area of mechanical studies.

In this study, the transnitrosation reaction of Senitrososelenols is investigated theoretically with the aim of gaining more detailed insight into the associated reaction thermodynamics and mechanism in both gas and aqueous solution. Moreover, we anticipate that the results on Senitrososelenols can be used to make a fair comparison with the better-known sulfur analogues (S-nitrosothiol).

\section{Theoretical methods}

All calculations were performed using the Gaussian 03 program [36]. Parthiban and coworkers studied the gas- phase $\mathrm{S}_{\mathrm{N}} 2$ reactions of $\mathrm{Y}^{-}+\mathrm{CH}_{3} \mathrm{X} \rightarrow \mathrm{CH}_{3} \mathrm{Y}+\mathrm{X}^{-}(\mathrm{X}, \mathrm{Y}=\mathrm{F}$, $\mathrm{Cl}, \mathrm{Br}$ ) by using a series of high-level ab initio computational methods and eight DFT functionals, and concluded that the MPW1K functional performed the best among all the DFT functionals tested [37]. The MPW1K functional can be viewed as a reparameterized MPW1PW91 functional to fit the barriers of chemical reactions [38]. Accordingly, we chose MP2/6-31+G* and three hybrid DFT functionals (MPW1LYP, MPW1PW91 and MPW1K) with the same basis set for this study [39, 40]. The core electron excitations are neglected in our MP2 calculation. When the same exchange functional (MPW) is used, the influence on the results of changing the correlation functional (MPW1LYP) or hybridization parameters (MPW1PW91) can be extracted from comparison of the results of hybrid DFT functionals (hereafter designated as MP2, MPW1LYP, MPW1PW91 and MPW1K). All the stationary points have been positively identified as equilibrium structures (the numbers of imaginary frequency $(\mathrm{NIMAG}=0)$ ) or transition states $(\mathrm{NIMAG}=1)$. For all transition states, motion corresponding to the imaginary frequency is checked visually. To obtain more accurate energetic values, singlepoint energy calculations were also performed at the $\mathrm{BD}$ (T)/D95+*//MP2/6-31+G* [41] and added to the MP2optimized zero-point vibrational energies [hereafter designated $\mathrm{BD}(\mathrm{T})]$. All energetic values mentioned are corrected for unscaled zero-point vibrational energies. Additionally, we performed NBO analysis to investigate the differences between S-nitrosothiols and Se-nitrososelenols [42]. Polarizable continuum models (PCM), in which the cavity is created via a series of overlapping spheres, were used to consider the solvent effect of water on the transnitrosation reaction [43]. The temperature of the aqueous solution was set to $310.0 \mathrm{~K}$, simulating body temperature, to mimic physiological conditions. The most naturally abundant isotopes were chosen for every element.

\section{Results and discussion}

The optimized DFT functional and basis set

Table 1 lists the calculated energetic values of the identity reaction $\mathrm{MeSNO}+\mathrm{SMe}^{-} \rightarrow \mathrm{MeSNO}+\mathrm{SMe}^{-}$based on the 
Table 1 The calculated $E_{\mathrm{COM}}$ (in kcal mol $\left.{ }^{-1}\right), E_{\mathrm{TS}}$ and the energy of the intermediate $\left(E_{\mathrm{INT}}\right)$ of MeSNO $+\mathrm{SMe}^{-} \rightarrow \mathrm{MeSNO}^{-} \mathrm{SMe}^{-}$using various theoretical methods

\begin{tabular}{llllllll}
\hline & MP2 & MPW1LYP & MPW1PW91 & MPW1K & BD(T) & B3LYP $^{\mathrm{b}}$ & MPW1LYP' $^{2}$ \\
\hline $\mathrm{E}_{\mathrm{COM}}{ }^{\mathrm{a}}$ & -14.3 & -12.0 & -12.3 & -12.4 & -12.7 & -11.6 & -12.0 \\
$\mathrm{E}_{\mathrm{TS}}{ }^{\mathrm{a}}$ & -8.1 & -6.9 & -6.4 & -5.0 & -8.2 & -7.1 & -7.3 \\
$\mathrm{E}_{\mathrm{INT}}{ }^{\mathrm{a}}$ & -24.8 & -14.0 & -14.1 & -9.6 & -15.3 & -15.3 & -15.0 \\
\hline
\end{tabular}

${ }^{\mathrm{a}}$ The energy standard is the infinitely separated reactants

${ }^{\mathrm{b}}$ Results based on B3LYP/6-311+G*, see [20]

various theoretical methods applied in this study. For ease of comparison, previous available results are also listed in Table 1 [20]. It is reasonable to expect formation of a stable complex as S-nitrosothiol and thiolate ion approach each other. The stabilized energy with respect to the separated reactants is designated as $-E_{\mathrm{COM}}$. Notably, the optimized structures obtained using MP2, MPW1LYP, MPW1PW91 and MPW1K are all similar. Furthermore, according to our results, even with the same exchange functional, the combined correlation functional and the hybridization parameters of a hybrid DFT functional may alter the theoretical results significantly. As listed in Table 1, the MPW1LYP results seem to be the closest to those of BD (T). The barrier $\left(E_{\mathrm{a}}\right)$ of the transnitrosation reaction, defined as $E_{\mathrm{TS}}-E_{\mathrm{com}}$, is calculated to be 5.1 and $4.6 \mathrm{kcal} \mathrm{mol}^{-1}$ by MPW1LYP and $\mathrm{BD}(\mathrm{T})$, respectively. In contrast to a report by Parthiban [37], MPW1K performs the worst among the various theoretical methods tested in this study. The previous B3LYP results of Houk et al. [20] were also in agreement with those of $\mathrm{BD}(\mathrm{T})$, although the $\mathrm{B} 3 \mathrm{LYP}$ functional underestimated the barrier of the $\mathrm{S}_{\mathrm{N}} 2$ reaction concluded by Schaefer et al. [44]. Furthermore, the basis set effect on the transnitrosation reaction was investigated by comparing the results of MPW1LYP/6-311+ $\mathrm{G}^{*}$ (designated as MPW1LYP' in Table 1) with those of MPW1LYP/6-31+G*. Evidently, MPW1LYP' is closer to $\mathrm{BD}(\mathrm{T})$ than is MPW1LYP. Accordingly, the following discussion is based on the results of MPW1LYP'.

\section{Thermodynamic comparison of MeSNO and MeSeNO}

According to our previous study [45], the cis isomer of RSNO is more stable than the trans isomer, except for $3^{\circ}$ substituents like the $t$-Bu group. Thus, the discussion here is limited only to the cis form of MeSNO and MeSeNO. This adoption is simply in agreement with the experimental evidence that the $\mathrm{C}-\mathrm{Se}-\mathrm{N}-\mathrm{O}$ linkage of BpqSeNO adopts a syn conformation [34].

Based on MPW1LYP', the bond lengths of Se-N and S-N are calculated to be 2.05 and $1.85 \AA$, respectively. Note that the bond length of S-N calculated by MPW1LYP' (1.85 $\AA$ ) is longer than our previous $\mathrm{B} 3 \mathrm{P} 86 / 6-31++\mathrm{G}^{* *}$ result $(1.82 \AA)$ [45]. Moreover, the MPW1LYP'-optimized Se-N bond length is in good agreement with that observed in the Xray crystallographic study of BpqSeNO (2.08 §) [34].

According to our previous results on S-nitrosothiols [45], we found that two types of significant orbital interactions exist in S-nitrosothiols: the mesomeric effect $\left(\left(\mathrm{n}_{\mathrm{S}} \leftrightarrow \pi *_{\mathrm{N}-\mathrm{O}}\right)\right)$ and negative hyperconjugation $\left(\mathrm{n}_{\pi \mathrm{O}} \leftrightarrow \sigma *_{\mathrm{N}-\mathrm{S}}\right)$. Also, we have used the coordination of $\mathrm{BH}_{3}$ and $\mathrm{Cu}^{+}$to check the effect of individual interactions on the stabilities of S-nitrosothiols. It was found that the mesomeric effect was compensated by the columbic attraction between $\mathrm{N}$ and $\mathrm{O}$, with the net effect being a stabilizing factor on S-nitrosothiols. The high reactivity of S-nitrosothiol was due to the strong negative hyperconjugation. By NBO analysis, the strengths of the corresponding orbital interactions in Se-nitrososelenols can thus be extracted. Taking the mesomeric effect $\left(\mathrm{n}_{\mathrm{S}} \leftrightarrow \pi^{*}{ }_{\mathrm{N}-\mathrm{O}}\right)$ of S-nitrosothiols as an example, the interaction strength between $n_{\mathrm{S}}$ and $\pi^{*}{ }_{\mathrm{N}-\mathrm{O}}$ should be inversely proportional to the corresponding energy gap. According to second-order perturbation theory, the interaction energy $E^{(2)}$ of the mesomeric effect can be written as Eq. 1:

$E^{(2)}=2 \frac{\left\langle n_{s}\left|H_{i n t}\right| \pi_{N-o}^{*}\right\rangle^{2}}{E_{\pi_{N-0}^{*}}-E_{n_{s}}}$

where $E_{\mathrm{ns}}$ and $\mathrm{E}_{\pi * \mathrm{~N}-\mathrm{O}}$ are the energy of $\mathrm{n}_{\mathrm{S}}$ and $\pi^{*} \mathrm{~N}-\mathrm{O}$ orbitals, respectively, and $H_{\text {int }}$ is the interaction Hamiltonian. The number 2 on the right side of Eq. 1 indicates the number of electrons occupied on the $n_{S}$ orbital.

According to Eq. 1, the mesomeric effects are estimated to be 22.8 and $21.1 \mathrm{kcal} \mathrm{mol}^{-1}$ for MeSNO and MeSeNO, respectively, while $E^{(2)}$ of the negative hyperconjugation are 49.3 (MeSNO) and $61.7 \mathrm{kcal} \mathrm{mol}^{-1}$ (MeSeNO). Thus, Se-nitrososelenol has similar mesomeric strength but stronger negative hyperconjugation effects than does RSNO. The eigenvalues of the corresponding orbitals and their interaction energies are summarized in Table 2. For comparison, relevant data reported previously are also listed [46]. As listed in Table 2, MP2 seems to overemphasize the stability of MeSNO because it predicts lower negative hyperconjugation and stronger mesomeric effects as compared with B3P86 or MPW1LYP'. In addition to the different strength of orbital interactions, there may be other intrinsic properties that influence the stability order of 
Table 2 The eigenvalues of orbitals (in $\mathrm{eV}$ ) and their interaction energies (in $\mathrm{kcal} \mathrm{mol}^{-1}$ ) of RXNO $(\mathrm{X}=\mathrm{S}, \mathrm{Se})$

\begin{tabular}{lll}
\hline $\mathrm{RXNO}$ & $\mathrm{X}=\mathrm{S}$ & $\mathrm{X}=\mathrm{Se}$ \\
\hline $\mathrm{n}_{\pi \mathrm{O}}$ & -0.3621 & -0.3697 \\
& $-0.3672^{\mathrm{a}}$ & \\
$\mathrm{n}_{\mathrm{X}}$ & -0.2651 & -0.2440 \\
$\sigma_{\mathrm{X}-\mathrm{N}}{ }^{*}$ & $-0.2872^{\mathrm{a}}$ & -0.0384 \\
$\pi_{\mathrm{N}-\mathrm{O}}{ }^{*}$ & 0.0255 & \\
$\mathrm{E}^{(2)}$ of $\mathrm{n}_{\pi \mathrm{O}} \leftrightarrow \sigma * \mathrm{X}-\mathrm{N}$ & $0.0152^{\mathrm{a}}$ & -0.0827 \\
& -0.0499 & 61.7 \\
& $-0.1220^{\mathrm{a}}$ & \\
$\mathrm{E}^{(2)}$ of $\mathrm{n}_{\mathrm{X}} \leftrightarrow \pi^{*}{ }_{\mathrm{N}-\mathrm{O}}$ & 49.3 & 21.1 \\
& $42.5^{\mathrm{a}}$ & \\
& $29.0^{\mathrm{b}}$ & \\
\hline
\end{tabular}

${ }^{\text {a }}$ Results calculated by B3P $86 / 6-31++\mathrm{G}^{* *}$, see [45]

${ }^{\mathrm{b}}$ Values obtained by MP2/6-31+G*, see [46]

MeSNO and MeSeNO. For example, the $3 p-2 p$ orbital overlap in $\mathrm{S}-\mathrm{N}$ (MeSNO) is better than the $4 \mathrm{p}-2 \mathrm{p}$ orbital overlap in Se-N (MeSeNO). Based on these results, Snitrosothiols seem to be more stable than Se-nitroselenols. This relative stability order is also reflected from the calculated homolytic bond dissociation energy (BDE) of the $\mathrm{N}-\mathrm{S}$ bond in MeSNO and that of the $\mathrm{Se}-\mathrm{N}$ bond in MeSeNO. BDEs for S-N and Se-N bonds are calculated to be 24.8 and $20.8 \mathrm{kcal} \mathrm{mol}^{-1}$, respectively. Since the BDE of the N-S bond in RSNO was reported to be sensitive to the basis set, [47] we made attempts to apply a more sophisticated theoretical level, e.g. G2, to reinvestigate the BDEs of $\mathrm{N}-\mathrm{S}$ and $\mathrm{N}-\mathrm{Se}$ bonds. According to $\mathrm{G} 2$ results, BDEs of N-S and N-Se are calculated to be 29.6 and 24.4 $\mathrm{kcal} \mathrm{mol}^{-1}$, respectively [48]. To allow a fair comparison with previous results, our MPW1LYP' and G2-calculated BDEs are also listed in Table 3. Clearly, the MPW1LYP'optimized BDE of the $\mathrm{N}-\mathrm{S}$ bond is within the experimentally determined value (20-28 $\left.\mathrm{kcal} \mathrm{mol}^{-1}\right)$ for RSNO [49].

Table 3 Bond dissociation energy (BDEs; in $\mathrm{kcal} \mathrm{mol}^{-1}$ ) of $\mathrm{X}-\mathrm{N}$ bond in RXNO $(X=S, S e)$

\begin{tabular}{lll}
\hline & $\mathrm{X}=\mathrm{S}$ & $\mathrm{X}=\mathrm{Se}$ \\
\hline MPW1LYP' & $24.8^{\mathrm{c}}$ & 20.8 \\
G2 & $29.6^{\mathrm{c}}$ & 24.4 \\
B3P86/6-31++G**a & $35.4^{\mathrm{c}}$ & - \\
B3P86/6-311++G(3df,3pd) & $34.2^{\mathrm{c}}$ & - \\
\hline
\end{tabular}

${ }^{\mathrm{a}}$ Results obtained from [45]

${ }^{\mathrm{b}}$ Results obtained from [47]

${ }^{\mathrm{c}}$ The experimental value is $20 \sim 28 \mathrm{kcal} \mathrm{mol}^{-1}$, see [49]
Other possible reactions between RSNOs and thiols

Upon changing the reagent ratios and experimental conditions, evidence exists that other intermediates and products are formed by RSNOs with thiols (see e.g., [50]). For example, the reaction also often leads to the formation of a disulfide bond, and site-specific S-thiolation by RSNOs is emerging as a novel mechanism to modify proteins of functional importance. In addition to the reaction pathway, forming a disulfide bond, two other reaction pathways are also considered in this study (see Scheme 2). For simplicity, the methyl group is taken as the representative for both R and R' sites in this approach.

The reaction pathways 1 and 2 in Scheme 2 can be viewed as the transnitrosation reaction between RSNO and a neutral thiol, not a thiolate anion. Reaction pathway 1 can be recognized as a concerted reaction, while reaction pathway 2 is a stepwise reaction in that the reactants undergo TS2 to obtain an intermediate, INT2, followed by a TS21 process to obtain the products. Reaction pathway 3 offers a possible mechanism to form a disulfide bond between RSNOs and thiols, affording HNO and RSSR' by a concerted mechanism. It is possible that $\mathrm{HNO}$ is further dissociated, giving rise to a proton and $\mathrm{NO}^{-}$. Similarly, prior to the infinite separation of HNO and RSSR' from TS, it is expected that a stable complex, defined as ProdCOM, can be formed via certain attractive long-distance interactions such as van der Waals forces. Figure 1 summarizes the optimized geometries of the relevant complexes (COM and ProdCOM), intermediates (INT), and transition states (TS) regarding the transnitrosation reaction; the corresponding reaction pathways are shown in Scheme 2 (with MeSNO and MeSH as the representatives). The calculated energetic values of all reactions mentioned are summarized in Table 4. As shown in Table 4, the transnitrosation reaction by MeSNO is more favorable with $\mathrm{MeS}^{-}$ than with MeSH. The overall mechanism of the transnitrosation reaction between MeSNO and $\mathrm{MeSH}$ can be summarized thus: MeSH dissociates to a proton and a thiolate that immediately acts as a nucleophile to attack MeSNO (see Scheme 1). This result is in agreement with that reported by Barnett et al. [15] who, according to the correlation between the rate constant of the transnitrosation reaction and $\mathrm{pH}$ values, concluded that transnitrosation occurs via the thiolate anion. Moreover, the reaction pathway yielding a disulfide bond (pathway 3 ) is thermodynamically unfavorable.

Kinetic comparison between S-nitrosothiols and Se-nitrososelenols

As shown in Table 4, transnitrosation between S-nitrosothiols and thiolate anions is the most favorable pathway kinetically. Therefore, we investigated similar reactions between $\mathrm{MeSeNO}$ and $\mathrm{SMe}^{-}$or $\mathrm{SeMe}^{-}$. Figure 2 shows the optimized 
Scheme 2 Other possible reaction pathways between S-nitrosothiols and thiols

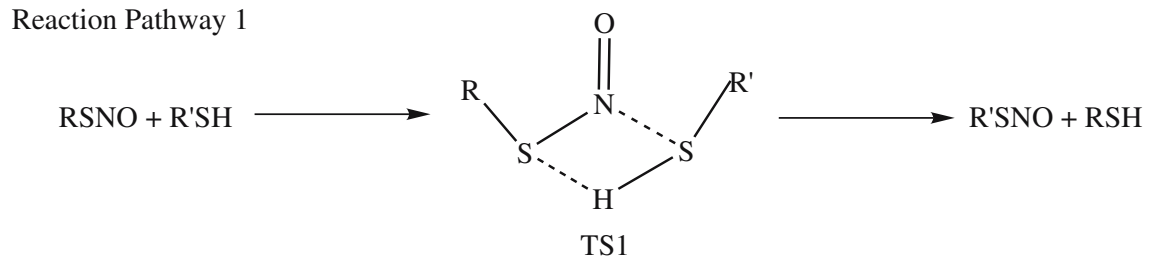

Reaction Pathway 2

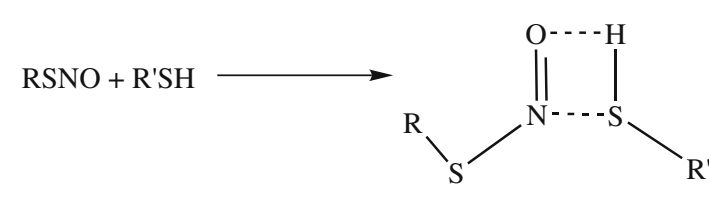

TS2<smiles></smiles>

TS21

Reaction Pathway 3

$\mathrm{RSNO}+\mathrm{R}^{\prime} \mathrm{SH}$<smiles>[R]S1=S([R])N([O])S1</smiles>

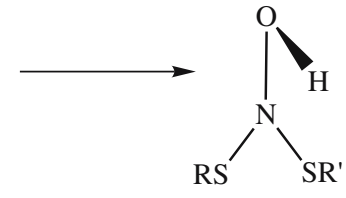

INT2

R'SNO + RSH
TS3 structures of these two anionic reactions, the results of which are similar to TS and INT depicted in Fig. 1, except for COM. The energies calculated by MPW1LYP' for complexes, intermediates and TSs are summarized in Table 5. As listed in Table 5, the reaction barriers of MeSeNO with respect to $\mathrm{SMe}^{-}$or $\mathrm{SeMe}^{-}$are calculated to be 8.5 and $7.5 \mathrm{kcal} \mathrm{mol}^{-1}$, respectively. The transnitrosation reaction between MeSNO and $\mathrm{SeMe}^{-}$can be viewed as the reverse reaction of $\mathrm{MeSeNO}+\mathrm{SMe}^{-}$, and its barrier can thus be estimated via $E_{\mathrm{TS}},-E_{\mathrm{COM}}$. Accordingly, the barriers of the transnitrosation reaction of MeSNO with respect to $\mathrm{MeS}^{-}$and $\mathrm{MeSe}^{-}$are deduced to be 4.7 and $4.7 \mathrm{kcal} \mathrm{mol}^{-1}$, respectively. Independent of the nucleophile, i.e., $\mathrm{SMe}^{-}$or $\mathrm{SeMe}^{-}$, the barrier of the transnitrosation reaction of MeSeNO is larger than that of MeSNO. Furthermore, we adopt a parameter expressed in Eq. 2 to check the change of $\mathrm{r}_{\mathrm{X}-\mathrm{N}}$ of $\mathrm{RXNO}(\mathrm{X}=$ $\mathrm{S}, \mathrm{Se}$ ) during transnitrosation:

$$
\begin{aligned}
(\% \circ f X-N)_{R X N O}= & \frac{\left|r_{X-N}(T S)-r_{X-N}(R X N O)\right|}{r_{X-N}(R X N O)} \\
& \times 100 \%
\end{aligned}
$$

where $r_{X-N}$ is the bond length of $\mathrm{X}-\mathrm{N}$ of $\mathrm{RXNO}(\mathrm{X}=\mathrm{S}, \mathrm{Se})$ and the symbols TS and RXNO in parentheses represent transition state and reactant, respectively. For MeSNO, this parameter is calculated to be $2.8 \%$ for both $\mathrm{MeS}^{-}$and $\mathrm{MeSe}^{-}$. For MeSeNO, it is deduced to be $3.0 \%$ for both $\mathrm{MeS}^{-}$and $\mathrm{MeSe}^{-}$. Note that the changes of $\mathrm{X}-\mathrm{N}$ bond distances are very small in all TSs, indicating that all TSs being calculated should be ascribed to early TSs.

\section{Transnitrosation reactions in aqueous solution}

Finally, the solvent effect of water on various transnitrosation reactions was investigated by full optimization (see Theoretical methods). Interestingly, the bond length of $\mathrm{S}-\mathrm{N}$ of MeSNO is shortened from $1.85 \AA$ in the gas phase to $1.78 \AA$ in aqueous solution. The same change can be seen regarding the length of the $\mathrm{Se}-\mathrm{N}$ bond in $\mathrm{MeSeNO}$. Some critical geometries parameters of relevant complexes and TSs are summarized in Fig. 3. As shown in Fig. 3, in transition states, the distances between electrophile and nucleophile are all shortened when considering the aqueous solvation. Taking $\mathrm{MeSNO}+\mathrm{SMe}^{-}$as an 


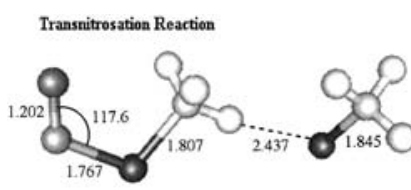

сом

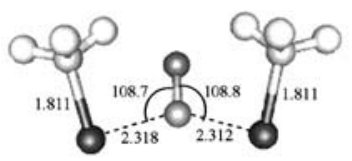

INT

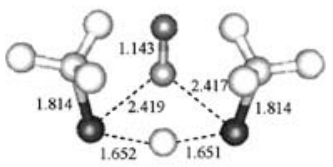

TS1

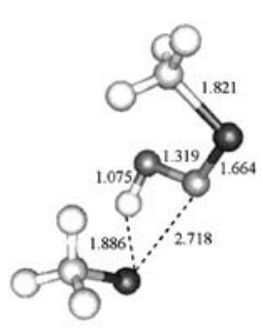

TS2

Pathway 3 in Scheme 2

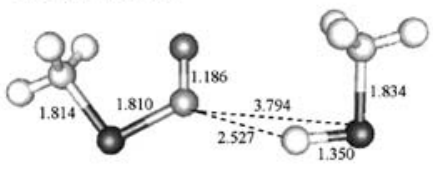

сом3

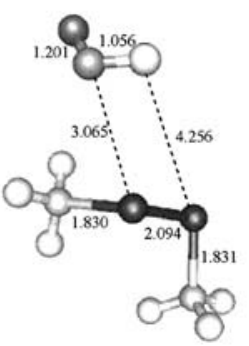

ProdCOM3

Fig. 1 The optimized geometries of the relative complexes (COM), intermediates (INT) and transition states (TS) of all mentioned reaction pathways between MeSNO and MeSH (COM, INT, TS for transnitrosation, COM1, TS1 for pathway 1 in Scheme 2, COM2, TS2, INT2 for pathway 2 in Scheme 2, and COM3, TS3, ProdCOM3 for pathway 3 in Scheme 2; bond length in $\AA$, bond angle in ${ }^{\circ}$, the colors of atoms change fromdark gray to white according to their atomic numbers)

Table 4 The energies (in $\mathrm{kcal} \mathrm{mol}^{-1}$ ) of various complexes (COM), intermediates (INT), transition states (TS) and product complexes (ProdCOM) formed by MeSNO and MeSH

\begin{tabular}{llllll}
\hline & $\mathrm{E}_{\mathrm{COM}}{ }^{\mathrm{a}}$ & $\mathrm{E}_{\mathrm{TS}}{ }^{\mathrm{a}}$ & $\mathrm{E}_{\mathrm{INT}}{ }^{\mathrm{a}}$ & $\mathrm{E}_{\text {ProdCOM }}{ }^{\mathrm{a}}$ & $\mathrm{E}_{\text {Prod }}{ }^{\mathrm{a}}$ \\
\hline Transnitrosation & -12.0 & -7.3 & -15.0 & -12.0 & 0.0 \\
Pathway 1 & -1.7 & 20.2 & & -1.7 & 0.0 \\
Pathway 2 & -1.3 & 43.6 & 11.6 & -1.3 & 0.0 \\
Pathway 3 & -1.3 & 45.3 & & 8.7 & 10.7 \\
\hline
\end{tabular}

${ }^{\mathrm{a}}$ The energy standard is the infinitely separated reactants

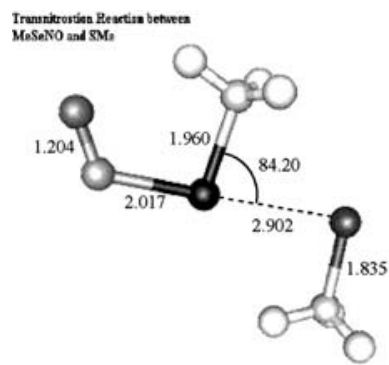

(Se, S) COM

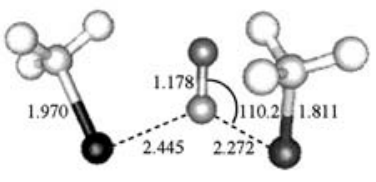

(Se, S) INT

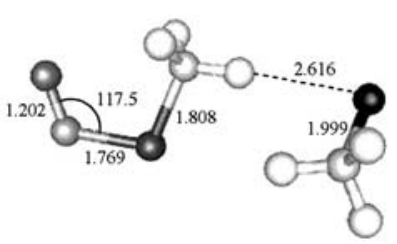

(Se, S) COM'

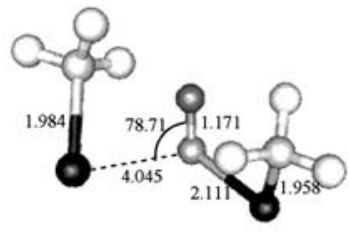

(Se, Se) TS

Fig. 2 The optimized geometries of the relative complexes, intermediates and transition states of the transnitrosation reactions between $\mathrm{MeSeNO}$ and $\mathrm{SMe}^{-}$or $\mathrm{SeMe}^{-}$. The parentheses (Se, S) respresent transnitrosation reaction between $\mathrm{MeSeNO}$ and $\mathrm{MeS}^{-}$, and the parentheses ( $\mathrm{Se}, \mathrm{Se}$ ) represent transnitrosation reaction between $\mathrm{MeSeNO}$ and $\mathrm{SeMe}^{-}$; bond length in $\AA$, bond angle in ${ }^{\circ}$, the colors of atoms change fromblack to white according to their atomic numbers 
Table 5 The calculated energies (in $\mathrm{kcal} \mathrm{mol}^{-1}$ ) of complexes, intermediates, $\mathrm{TSs}$ of $\mathrm{MeSeNO}+\mathrm{MeY}^{-}(\mathrm{Y}=\mathrm{S}, \mathrm{Se})$

\begin{tabular}{lll}
\hline & $\mathrm{Y}=\mathrm{S}$ & $\mathrm{Y}=\mathrm{Se}$ \\
\hline $\mathrm{E}_{\mathrm{COM}}{ }^{\mathrm{a}}$ & -16.2 & -13.9 \\
$\mathrm{E}_{\mathrm{TS}}{ }^{\mathrm{a}}$ & -7.7 & -6.4 \\
$\mathrm{E}_{\mathrm{INT}}{ }^{\mathrm{a}}$ & -18.3 & -15.6 \\
$\mathrm{E}_{\mathrm{TS1}}{ }^{\mathrm{a}}$ & -11.9 & -6.4 \\
$\mathrm{E}_{\text {ProdCOM }}{ }^{\mathrm{a}}$ & -16.6 & -13.9 \\
$\mathrm{E}_{\text {Prod }}{ }^{\mathrm{a}}$ & -5.8 & 0.0 \\
\hline
\end{tabular}

${ }^{\mathrm{a}}$ The energy standard is the infinitely separated reactants

example, the distance between sulfur on $\mathrm{SMe}^{-}$and $\mathrm{N}$ on MeSNO is shortened from $3.67 \AA$ in the gas phase to $2.85 \AA$ in aqueous solution. Furthermore, we cannot locate any intermediate under aqueous solution. Accordingly, all transnitrosation reactions are found to be concerted
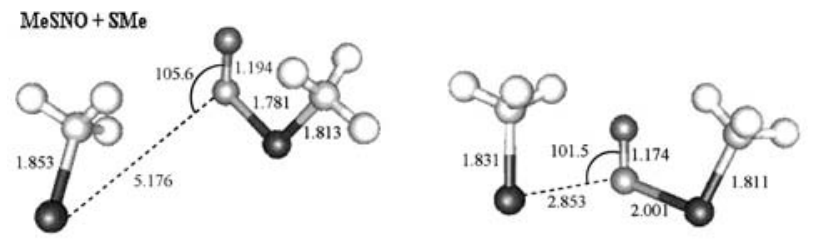

COM in water

TS in water

$\mathrm{MeSeNO}+\mathrm{SMe}$
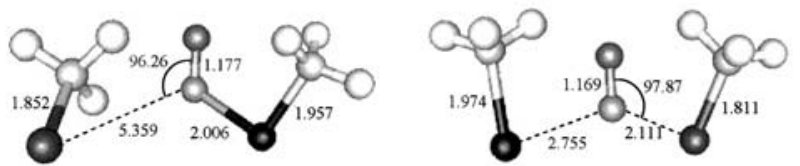

(Se, S)COM in water

$(\mathrm{Se}, \mathrm{S}) \mathrm{TS}$ in water

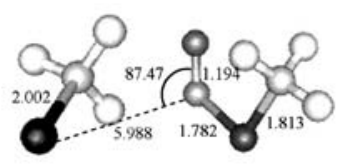

(Se, S)COM' in water

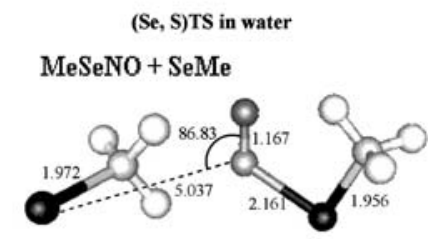

(Se, Se)COM in water

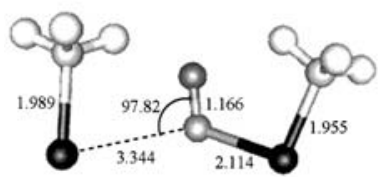

(Se, Se)TS in water

Fig. 3 The optimized geometries of the relative complexes, intermediates and transition states of the transnitrosation reactions in aqueous solution (COM and TS for transnitrosation between MeSNO and $\mathrm{SMe}^{-}$. The parentheses $(\mathrm{Se}, \mathrm{S}$ ) respresent the transnitrosation reaction between $\mathrm{MeSeNO}$ and $\mathrm{MeS}^{-}$, and the parentheses (Se, Se) respresent the transnitrosation reaction between $\mathrm{MeSeNO}$ and $\mathrm{SeMe}^{-}$; bond length in $\AA$, bond angle in ${ }^{\circ}$, the colors of atoms change from black to white according to their atomic numbers reactions, the results of which are drastically different from that in the gas phase (vide supra). Notably, the complexes designated as $\mathbf{C O M}$ and (Se, S)COM' in water are not minima on the potential energy surfaces. By vibrational frequency analysis, they have at least one imaginary frequency and $\mathrm{NIMAG}=1$ and 2 for $\mathrm{COM}(34 i)$ and $(\mathrm{Se}, \mathrm{S}) \mathrm{COM}^{\prime}(33 i, 11 i)$, respectively, in water. Table 6 summarizes the main differences of the results in gas phase and aqueous solution. Clearly, the barriers of the transnitrosation reactions of MeSNO are decreased by 2.0 and $2.5 \mathrm{kcal} \mathrm{mol}^{-1}$ for nucleophiles $\mathrm{SMe}^{-}$and $\mathrm{SeMe}^{-}$, respectively, from gas phase to aqueous solvation. Furthermore, the transnitrosation reactions of $\mathrm{MeSeNO}$ can be said to be barrierless in aqueous solution. All $\% \mathrm{X}-\mathrm{N}$ are larger in aqueous solution than in the gas phase. That is to say, the TSs are further from the reactants if considering the solvent effect of water. Nevertheless, they are still early TSs. Houk et al. have reoptimized the gas-phase structure of nitroxyl disulfide after distorting one of the S-N bonds by about $0.1 \AA$ to consider aqueous solvation, and they gained minima that are neither reactants nor products [33]. Therefore, they concluded that an intermediate exists but with a short life span, the result of which is different from our fully optimized results. This discrepancy could be due to the solution temperature being set at $310.0 \mathrm{~K}$ in this study.

\section{Conclusions}

In conclusion, the above results show that the transnitrosation reaction is a stepwise and an anionic $\mathrm{S}_{\mathrm{N}} 2$ reaction between RSNO and thiolate in the gas phase but, in sharp contrast, it may be a concerted reaction in aqueous solution at $310.0 \mathrm{~K}$. Furthermore, Se-nitrososelenols are more unstable than S-nitrosothiols for unimolecular decomposition. Comparing $\mathrm{MeSeNO}$ with $\mathrm{MeSNO}$, the $\mathrm{Se}-\mathrm{N}$

Table 6 The barriers (in $\mathrm{kcal} \mathrm{mol}^{-1}$ ) and $\% \mathrm{X}-\mathrm{N}$ of RXNO of the transnitrosation reactions $\mathrm{MeXNO}+\mathrm{MeY}^{-}(\mathrm{X}=\mathrm{S}$, Se; $\mathrm{Y}=\mathrm{S}, \mathrm{Se})$

\begin{tabular}{lll}
\hline$(\mathrm{X}, \mathrm{Y})$ & $E \mathrm{a}$ & $\% \mathrm{X}-\mathrm{N}$ of RXNO \\
\hline$(\mathrm{S}, \mathrm{S})$ & 4.7 & $2.8 \%$ \\
& $2.2^{\mathrm{a}}$ & $12.3 \%$ \\
$(\mathrm{~S}, \mathrm{Se})$ & 4.7 & $2.8 \%$ \\
& 2.7 & $18.5 \%$ \\
$(\mathrm{Se}, \mathrm{S})$ & 8.5 & 3.0 \\
& $-{ }^{\mathrm{b}}$ & $37.2 \%$ \\
$(\mathrm{Se}, \mathrm{Se})$ & 7.5 & $3.0 \%$ \\
& $-{ }^{\mathrm{b}}$ & $5.3 \%$ \\
\end{tabular}

${ }^{a}$ Values in italic type are in aqueous solution

${ }^{\mathrm{b}}$ The negative value obtained indicates that these reactions are barrierless 
bond in RSeNO is weaker than the $\mathrm{S}-\mathrm{N}$ bond in RSNO and its $\mathrm{BDE}$ is calculated to be $24.4 \mathrm{kcal} \mathrm{mol}^{-1}$ by $\mathrm{G} 2$. Interestingly, however, the barrier of the transnitrosation reaction of MeSeNO is larger than that of MeSNO, disregarding nucleophiles in the gas phase. The barriers of the transnitrosation reactions of MeSNO are found to be decreased for nucleophiles SMe- and SeMe- in going from the gas phase to aqueous solution, while the transnitrosation reactions of MeSeNO are essentially barrierless in aqueous solution. Apparently, solvent polarity plays a key role in the corresponding reaction dynamics. It is thus tentatively proposed that the activated complex, due to its negatively charged nature, may be more subject to solvent polarity interactions, resulting in a reduction in the reaction barrier. Finally, since \% X-N are very small in all TSs regardless of gas or aqueous solvation, all TSs calculated should be ascribed to early TSs, except that the TSs are further from the reactants in aqueous solution.

Acknowledgements We are grateful to the National Center for High-Performance Computing of Taiwan for allowing us generous amounts of computing time. We also thank the National Science Council for financial support.

\section{References}

1. Ignarro LJ, Buga GM, Word KS, Byrns RE, Chaudhuri G (1987) Proc Natl Acad Sci USA 84:9265-9269

2. Furchgott RF, Zawadzki JV (1980) Nature 288:373-376

3. Pfeiffer S, Mayer B, Hemmens B (1999) Angew Chem Int Ed 38:1714-1731

4. Al-Sa'Doni H, Ferro A (2000) Clin Sci 98:507-520

5. Azuma H, Ishikawa M, Sekizaki S (1986) Br J Pharmacol $88: 411-415$

6. Furlong B, Henderson AH, Lewis MJ, Smith JA (1987) Br J Pharmacol 90:687-692

7. Radomski MW, Palmer RMJ, Moncada S (1987) Br J Pharmacol 92:181-187

8. Radomski MW, Palmer RMJ, Moncada S (1987) Biochem Biophys Res Commun 148:1482-1489

9. Radomski MW, Palmer RMJ, Moncada S (1987) Lancet 2:10571058

10. Dicks AP, Williams DL (1996) Chem Biol 3:655-659

11. Park JW (1988) Biochem Biophys Res Commun 152:916-920

12. Meyer DJ, Kramer H, Ozer N, Coles B, Ketterer B (1994) FEBS Lett 345:177-180

13. Wong PS, Hyun J, Fukuto JM, Shirota FN, DeMaster EG, Shoeman DW, Nagasawa HT (1998) Biochemistry 37:5362-5371

14. Barnett DJ, McAninly J, Williams DLH (1994) J Chem Soc Perkin Trans 2:1131-1133

15. Barnett DJ, Rios A, Williams DLH (1995) J Chem Soc Perkin Trans 2:1279-1282

16. Scharfstein JS, Keaney JF, Slivka A, Welch GN, Vita JA, Stamler JS, Loscalzo J (1994) J Clin Invest 94:1432-1439

17. Park JW, Billman GE, Means GE (1993) Biochem Mol Biol Int 30:885-891
18. Giustarini D, Milzani S, Colombo R, Dalle-Donne I, Rossi R (2003) Clin Chim Acta 330:85-98

19. Dicks A, Li E, Munro A, Swift H, Williams D (1998) Can J Chem 76:789-794

20. Houk KN, Hietbrink BN, Bartberger MD, McCarren PR, Cho BY, Voyksner RD, Stamler JS, Toone EJ (2003) J Am Chem Soc 125:6972-6976

21. Singh PS, Wishnok JS, Keshive M, Deen WM, Tannebaum SR (1996) Proc Natl Acad Sci USA 93:14428-14433

22. Srivastava S, Dixit BL, Ramana KV, Chandra A, Chandra D, Zacarias A, Petrash JM, Bhatnagar A, Srivastava SK (2001) Biochem J 358:111-118

23. Laura LP, Adrián GT, Darío AE, Fabio D (2005) J Am Chem Soc 127:486-487

24. Freedman JE, Frei B, Welch GN, Loscalzo J (1995) J Clin Invest 96:394-400

25. Asahi M, Fujii J, Suzuki K, Seo HG, Kuzuya T, Hori M, Tada M, Fujii S, Taniguchi N (1995) J Biol Chem 270:21035-2039

26. Asahi M, Fujii J, Takao T, Kuzuya T, Hori M, Shimonishi Y, Taniguchi N (1997) J Biol Chem 272:19152-19157

27. Igarashi J, Nishida M, Hoshida S, Yamashita N, Kosaka H, Hori M, Kuzuya T, Tada M (1998) Am J Physiol 274:C245-C252

28. Fujii J, Taniguchi N (1999) Free Radical Res 31:301-308

29. Koh YH, Suzuki K, Che W, Park YS, Miyamoto Y, Higashiyama S, Taniguchi N (2001) FASEB J 15:1472-1474

30. Dobashi K, Asayama K, Nakane T, Kodera K, Hayashibe H, Nakazawa S (2001) Free Radical Res 35:319-327

31. Wismach C, du Mont W-W, Jones PG, Ernst L, Papke U, Mugesh G, Kaim W, Wanner M, Becker KD (2004) Angew Chem Int Ed 43:3970-3974

32. Shimada K, Goto K, Kawashima T, Takagi N, Choe Y-K, Nagase S (2004) J Am Chem Soc 126:13238-13239

33. Goto K, Shimada K, Kawashima T (2005) Phosphorus Sulfur Silicon 180:945-949

34. Goto K, Yamamoto G, Tan B, Okazaki R (2001) Tetrahedron Lett 42:4875-4877

35. Shimada K, Goto K, Kawashima T (2005) Chem Lett 34:654-655

36. Frisch MJ, Trucks GW, Schlegel HB, Scuseria GE, Robb MA, Cheeseman JR, Montgomery JA, Jr Vreyen T, Kudin KN, Burant JC, Millam JM, Iyengar SS, Tomasi J, Barone V, Mennucci B, Cossi M, Scalmani G, Rega N, Petersson GA, Nakatsuji H, Hada M, Ehara M, Toyota K, Fukuda R, Hasegawa J, Ishida M, Nakajima T, Honda Y, Kitao O, Nakai H, Klene M, Li X, Knox JE, Hratchian HP, Cross JB, Adamo C, Jaramillo J, Gomperts R, Stratmann RE, Yazyev O, Austin AJ, Cammi R, Pomelli C, Octhterski JW, Ayala PY, Morokuma K, Voth GA, Salvador P, Dannenberg JJ, Zakrzewski VG, Dapprich S, Daniels AD, Strain MC, Farkas O, Malick DK, Rabuck AD, Raghavachari K, Foresman JB, Ortiz JV, Cui Q, Baboul AG, Clifford S, Cioslowski J, Stefanov BB, Liu G, Liashenko A, Piskorz P, Komaromi I, Martin RL, Fox DJ, Keith T, AlLaham MA, Peng CY, Nanayakkara A, Challacombe M, Gill PMW, Johnson B, Chen W, Wong MW, Gonzalez C, Pople JA (2004) Gaussian 03, Revision C.02. Gaussian, Pittsburgh PA

37. Parthiban S, de Oliveira G, Martin JML (2001) J Phys Chem A 105:895-904

38. Lynch BJ, Fast PL, Harris M, Truhlar DG (2000) J Phys Chem A 104:4811-4815

39. Head-Gordon M, Pople JA, Frisch MJ (1988) Chem Phys Lett 153:503-506

40. Adamo C, Barone V (1998) J Chem Phys 108:664-675

41. Handy NC, Pople JA, Head-Gordon M, Raghavachari K, Trucks GW (1989) Chem Phys Lett 164:185-192 
42. Carpenter JE, Weinhold F (1988) Theochem 169:41-62

43. Miertus S, Scrocco E, Tomasi J (1981) Chem Phys 55:117-129

44. Gonzales JM, Pak C, Cox RS, Allen WD, Schaefer HF, Császár AG, Tarczay G (2003) Chem Eur J 9:2173-2192

45. Lai C-H, Li EY, Chou P-T (2007) Theor Chem Acc 117:145-152

46. Bharatam PV, Amita (2002) Tetrahedron Lett 43:8289-8291

47. Baciu C, Gauld JW (2003) J Phys Chem A 107:9946-9952
48. Curtiss LA, Raghavachari K, Trucks GW, Pople JA (1991) J Chem Phys 94:7221-7230

49. Lü JM, Wittbrodt JM, Wang K, Wen Z, Schlegel BH, Wang PG, Cheng JP (2001) J Am Chem Soc 123:2903-2904

50. Wong PSY, Hyun J, Fukuto JM, Shirota FN, DeMaster EG, Shoeman DW, Nagasawa HT (1998) Biochemistry 37:53625371 